\title{
La reproducción más allá de la extinción: cuidados desintoxificados en ficciones antropocénicas latinoamericanas
}

\author{
REPRODUCTION BEYOND HU/MAN EXTINCTION: DETOXIFYING CARE IN LATIN \\ AMERICAN ANTHROPOCENE FICTIONS ${ }^{1}$
}
REPRODUÇÃO ALÉM DA EXTINÇÃO: CUIDADO DESINTOXICADO EM FICÇÕES ANTROPOCÊNICAS DA AMÉRICA LATINA

\author{
Allison Eleanor Mackey *2 \\ amackey@fhuce.edu.uy
}

\section{Resumen}

Las ansiedades en torno a la paternidad fallida están vinculadas a la gestión fallida del planeta por parte de la humanidad en mucha ficción contemporánea que refleja una cierta conciencia antropocénica. Sin embargo, la figura del niño humano biológico, como el significante del futuro, llama la atención sobre la dificultad de imaginar el futuro de manera no heteronormativa y no antropocéntrica. La reproducción no es más que una réplica de lo mismo, de formas de vida que son como nosotros. Para recuperar un modelo alternativo de cuidado de su linaje antropocéntrico, en este trabajo examino cómo el relato de ciencia ficción feminista de Anacristina Rossi, "Abel" '(2013) y la novela eco-gótica de Samantha Schweblin Distancia de Rescate (2015) realizan críticas radicales a la idea de cuerpos reproductivos, mientras que se abren para señalar posibilidades de vida no binarias. De esta manera ofrecen una crítica a nivel de especie al mismo tiempo que permanecen arraigados a geografías locales. Estas narrativas especulativas abarcan las implicaciones negativas del pensamiento antropocénico, desafiando, reflexionando y perpetuando las ansiedades en torno a la diferencia sexual y la posibilidad de extinción humana, sin depender de mandatos esencializadores sobre la feminidad, la maternidad y el cuidado. Se involucran con lo que Claire Colebrook llama "extinción figurativa" como una forma de señalar la posibilidad de alejarse de visiones de cuidado históricamente tóxicas (androcéntricas, capitalistas y antropocéntricas) y hacia una ética de conexión multiespecies.

Palabras clave: narrativas antropocénicas; posthumanismo feminista; ecocrítica

\footnotetext{
${ }^{1}$ Traducción del artículo publicado en Feminist Encounters: A Journal of Critical Studies in Culture and Politics. 5(1), 06 (número especial sobre género y el antropoceno editado por Amanda Gouws, Dierdre Byrne y Azille Coetzee), 5 de marzo, 2021. eISSN: 2468-4414.

2 * Facultad de Humanidades y Ciencias de la Educación, Universidad de la República

Tekoporá ${ }^{\circledR}$. Centro Universitario de la Región Este. Universidad de la República (C) Mackey. (2021)

Este es un artículo de Acceso Abierto distribuido bajo licencia Creative Commons (CC BY NC 4.0)
} 
materialista; género y extinción; eco-ficción latinoamericana

\begin{abstract}
Anxieties around failed parenting are linked to humanity's failed stewardship of the planet in many recent Anthropocene narratives, yet the figure of the biological human child, as the signifier of futurity draws attention to the difficulty of imagining the future in non-heteronormative, non-Western, and non-anthropocentric terms. Reproduction is nothing if not a replication of self, of forms of life that are like us. In order to recuperate an alternative model of care from its anthropocentric lineage, I examine how Anacristina Rossi's feminist sci-fi story "Abel" (2013) and Samantha Schweblin's novella Distancia de Rescate (2014) perform radical critiques of the idea of reproductive bodies, while at the same time opening out to signal non-binary possibilities of life, offering species-level critique while at the same time remaining rooted in local geographies. These stories embrace the negative implications of Anthropocene thinking, challenging, reflecting, and perpetuating anxieties around sexual difference and the possibility of human extinction, without relying on essentialised mandates about femininity, childbearing and caregiving. They engage with what Claire Colebrook calls "figural extinction" as a way to signal the possibility of moving away from historically toxic androcentric, capitalist and anthropocentric visions of care, and toward an ethic of non/human connection.
\end{abstract}

Keywords: anthropocene narratives, feminist posthumanism, materialist eco-criticism, gender and extinction, Latin American eco-fiction

\title{
Resumo
}

As ansiedades em torno do fracasso dos pais estão ligadas ao fracasso da gestão do planeta pela humanidade em muitas narrativas recentes do Antropoceno, mas a figura da criança humana biológica, como ${ }^{*}{ }^{*}{ }^{*}$ significante de futuridade chama a atenção para a dificuldade de imaginar o futuro em não heteronormativo termos, não ocidentais e não antropocêntricos. A reprodução não é nada senão uma replicação de si mesmo, de formas de vida que são como nós. A fim de recuperar um modelo alternativo de cuidado de sua linhagem antropocêntrica, examino como a história de ficção científica feminista de Anacristina Rossi "Abel" (2013) e a novela de terror gótico de Samantha Schweblin Distancia de Rescate (2014) fazem críticas radicais à ideia de corpos reprodutivos, enquanto ao mesmo tempo, abrindo-se para sinalizar possibilidades não binárias de vida, oferecendo uma crítica em nível de espécie e, ao mesmo tempo, permanecendo enraizado em geografias locais. Essas histórias abrangem as implicações negativas do pensamento Antropoceno, desafiando, refletindo e perpetuando ansiedades em torno da diferença sexual e da possibilidade de extinção humana, sem depender de mandatos essencializados sobre feminilidade, gravidez e cuidados. Eles se engajam no que Claire Colebrook chama de "extinção figural" como uma forma de sinalizar a possibilidade de se afastar de visões de cuidado historicamente tóxicas, androcêntricas, capitalistas e antropocêntricas e em direção a uma ética de conexão não/humana.

Palavras-chave: narrativas antropocênicas, pós-humanismo feminista, eco-crítica materialista, gênero e extinção, eco-ficção latino-americana 
[E]l evento que finalmente precipitará la extinción humana no es su apertura radical a la disolución, sino su

autoenclavamiento suicida, su integridad autolimitada que sólo le permitirá imaginar su propio mundo desde su propio horizonte imaginativo. ${ }^{3}$

$$
\text { Claire Colebrook, “Sexual Indifference” (2012) }
$$

Me acordé de Noé pero después me reí, esto no era el Génesis, era el cambio climático.

Anacristina Rossi, “Abel” (2013)

Este artículo se concentra en cómo se representa la reproducción humana "fallida" para abordar "las desastrosas consecuencias planetarias de nuestra especie y el violento gobierno del Antropos soberano" (Braidotti, 2019, p.10) en dos ejemplos contemporáneos de ficción antropocénica latinoamericana: "Abel" de Anacristina Rossi y Distancia de rescate de Samantha Schweblin. ${ }^{4}$ Leyéndolos juntos con teoría feminista materialista y ecocrítica posthumanista, analizo cómo estos textos representan la reproducción sin generación como un replanteamiento de las relaciones de cuerpo y producción, además de comentar sobre futuros post-humanos. Señalando la forma en que ambos textos postulan la naturaleza no-humana como una "fuerza agencial que participa activamente en la configuración material-discursiva del mundo con implicaciones políticas, éticas y ecológicas de gran alcance" (Coleman, 2016, p. 697), mi objetivo es participar de un proyecto crítico que expande los "horizontes de la crítica ambiental latinoamericana al comprometerse con textos que no suelen incluirse en los debates eco críticos" (ibid). Hago hincapié en cómo realizan una crítica radical de la prioridad antropocéntrica de los cuerpos reproductivos en el momento contemporáneo, abriéndose para incorporar comprensiones no binarias de un devenir [becoming] múlti-especie. Como dicen Serenella Iovino y Serpil Oppermann (2012), esto "incluye la materialidad vital de la vida, las experiencias de entidades no humanas y nuestras intra-acciones corporales con todas las

\footnotetext{
${ }^{3}$ Todas las traducciones del inglés de este artículo son propias. En el caso de fragmentos más largos, ofrezco también las citas originales: "[T]he event that will ultimately precipitate human extinction is not its radical openness to dissolution but its suicidal self-enclosure, its self-bounded integrity that will allow it only to imagine its own world from its own imaginative horizon."

${ }^{4}$. Tomo prestado el término útil de Adam Trexler "ficciones antropocénicas" [Anthropocene fictions] para describir estas obras, entendiendo el término no solo en un sentido temporal (es decir, para describir textos publicados desde el cambio de milenio), sino también para señalar una cierta (auto) conciencia en tales narrativas sobre los impactos antropogénicos en el medio ambiente. Centrándose específicamente en el género de la novela, el objetivo central de Trexler es establecer "cómo el cambio climático y todas sus cosas han cambiado las capacidades de la literatura reciente" (p. 13). En otras palabras, las ficciones del Antropoceno no son solo sobre el Antropoceno, sino también son productos del Antropoceno.
} 
formas de agencia material como actores efectivos" (p. 88). Esta revalorización provoca una suspensión de conceptos antropocéntricos a medida que los actos sexuales, la reproducción y las nociones tradicionales de cuidado de futuras generaciones, se ponen en tela de juicio frente a formas que van más allá de las lógicas cartesianas, y más hacia lo que Karen Barad (2003) llama relaciones "intra-activas", donde la presunta primacía del humano está socavada.

En pocas palabras, participar en la crianza de los hijos es participar en la reproducción del futuro de la humanidad. Sin embargo, la publicación de Instagram de la congresista estadounidense Alexandria Ocasio-Cortez en 2019, preguntando si, dado que "hay un consenso científico de que la vida de los niños va a ser muy difícil (...) ¿todavía está bien tener hijos?" resuena con la formación reciente de organizaciones voluntarias contra la procreación (BirthStrike, por ejemplo) para hombres y mujeres que han decidido no tener hijos en respuesta al cambio climático, en un "reconocimiento radical" de cómo esta amenaza existencial que se avecina ya está "alterando la forma en que imaginamos nuestro futuro" (Hunt, $2019 \mathrm{np}$ ). La ansiedad sobre tener hijos frente al "colapso del clima y el colapso de la civilización" (ibid) también se refleja en una larga lista de ficciones antropocénicas que han ido surgiendo en la Anglósfera en los últimos años. En una creciente proliferación de relatos que presentan unidades familiares destripadas, niños abandonados, y embarazos monstruosos en una época de colapso climático, una sensación de ruina inminente en torno a la noción de paternidad/maternidad fallida está cada vez más vinculada a la gestión fallida del planeta por parte de la humanidad. ${ }^{5}$ Adeline Johns-Putra (2014) identifica que la presunción en tales narrativas es que, para contrarrestar la "arrogancia colectiva" de la humanidad, el único "camino a seguir" se basa en una noción de cuidado del medio ambiente que se entiende en gran medida en términos de culpabilidad intergeneracional (p.128). Las preocupaciones narrativas centradas en la "figura del niño", como "sujeto primordial de protección, refugio y tutela", resuenan con "las ansiedades contemporáneas sobre si estamos haciendo lo suficiente para proteger, albergar y salvaguardar aquello de lo que somos responsables" (Johns-Putra, 2016, p. 523). Greta Thunberg y el fenómeno Fridays for Future han dejado en claro que los cálculos de culpabilidad intergeneracional por el mundo arruinado que nuestros hijos han heredado se han convertido en un elemento fundamental de las narrativas que nos estamos contando sobre la posibilidad del futuro en el momento actual.

Como señaló Lee Edelman en su libro seminal No Future (2004) "no somos más capaces de concebir una política sin una fantasía del futuro de lo que somos capaces de concebir un futuro sin la figura del Niño" (p. 11). Sin embargo, como esclarece la crítica que realiza Edelman sobre el "futurismo reproductivo", la figura

\footnotetext{
5. Por ejemplo, ansiedades sobre la (im)posibilidad de cuidar a los niños en el contexto del Antropoceno impregnan a novelas anglófonas como Weather (2020) por Jenny Offill, Sealed (2017) por Naomi Booth, The End We Start From (2017) por Megan Hunter, Clade (2015) por James Bradley, The World Without Us (2015) por Mireille Juchau, The History of Bees (2015) por Maja Lunde, Gold, Fame, Citrus (2015) por Claire Vaye Watkins, Heroes of the Frontier (2016) por Dave Eggers, The Bear, por Andrew Krivak (2020), y (de manera particularmente mordaz) en The Children's Bible (2020) por Lydia Millet.
} 
normativa del niño humano biológico, como significante del futurismo por excelencia, no solo llama la atención sobre la dificultad de imaginar el futuro en términos no heteronormativos sino que también habla de las formas sexistas y esencialistas en las que el cuidado reproductivo se asocia inevitablemente con la "madre" naturaleza. ${ }^{6}$ Además, lo que se lamenta en muchas visiones post-apocalípticas del fin del mundo es, como sugiere Johns-Putra, "la pérdida de la naturaleza humana en lugar de la no humana" (2016, p. 521). Claire Colebrook (2012) señala cómo las ansiedades contemporáneas en torno a la "extinción de la diferencia sexual-tanto la relación necesaria de la sexualidad con la extinción como la posibilidad de que la diferencia sexual misma se extinga"-ha parecido "provocar un retorno o un retroceso a la figura de la pareja sexual" dentro de la cultura popular (p. 168). A juzgar por mucha de la producción cultural de los últimos años, a pesar de que "muchas especies ya se reproducen sin reproducción sexual dual, o vía reproducción sexual que no genera sexos diferenciados" (ibid), parece que nuestra propia noción de futuro depende únicamente de la reproducción sexual de la especie humana.

La reproducción no es más que una réplica de lo mismo, de formas de vida que son como nosotros. Atrapados dentro de lógicas normativas de la autorreplicación incluso cuando imaginamos interminablemente nuestro propio fin en una miríada de géneros culturales, seguimos siendo incapaces de valorar formas de vida que radicalmente no son como nosotros; somos incapaces de entender nuestro parentesco y dependencia existencial en formas de vida que son distintas o más-que-humanas. Pero, ¿cómo sería entender la reproducción y las relaciones de cuidado en términos post-humanos? Aquí entiendo el poshumanismo en el sentido de Rosi Braidotti (2019), como una crítica no reduccionista del humanismo y del antropocentrismo, basada en última instancia en la multiplicidad, donde se asume un "nosotros" no universal (p. 9). De manera similar, Karen Barad (2003) sugiere que el posthumanismo ofrece "un relato que cuestiona el carácter dado de las categorías diferenciales de 'humano' y 'no humano', examinando las prácticas a través de las cuales estos límites diferenciales se estabilizan y desestabilizan" (p. 808). El objetivo subyacente del pensamiento posthumanista es cambiar el plano epistemológico desde una posición antropocéntrica que presume la hegemonía de lo "humano" (léase: sujeto cis masculino, encerrado en sí mismo, que subsume todo lo demás bajo su ser logocéntrico encarnado) a un plano inmanente de relacionalidad, mucho más fluido, donde el humano es simplemente un pariente entre muchos. En este reposicionamiento, todas las cosas (incluso "nosotros") adquieren realidad ontológica dentro de una relación de igualdad radical, donde una posición externa o superior (como Anthropos) ya no es sostenible.

\footnotetext{
6. Películas como Mother! (dir Darren Aaronofsky, 2017) se basan en una visión de género de la tierra como madre, transformándola de una madre viva a un cuerpo femenino pasivo. De hecho, en una larga lista de películas de ciencia ficción, la agencia retributiva de la tierra se representa como "venganza": la tierra es una figura caprichosa que es indiferente al bienestar de sus "hijos", y cuyas acciones vengativas se representan como "El producto de la emoción, el resultado de la subjetividad femenina pobremente constreñida, clamando por la disciplina racionalizada históricamente asociada con las nociones occidentales de masculinidad" (Mitchell, 2015, np).
} 
Con el fin de recuperar un modelo alternativo de una ética de cuidado de su linaje antropocéntrico, en las páginas restantes exploraré cómo las narrativas que he elegido se centran en la diferencia sexual y la reproducción con el fin de lanzar una crítica a nivel de especie, mientras que al mismo tiempo permanecen arraigadas en geografías locales. Rossi y Schweblin desafían, reflexionan y perpetúan ansiedades en torno a la diferencia sexual y la posibilidad de la extinción humana sin depender de mandatos esencializadores sobre la feminidad, la maternidad y el cuidado. En cada uno de los textos, la seguridad de la unidad familiar, que es ostensiblemente un espacio de protección, resulta ser una ilusión peligrosa que es literalmente, así como figurativamente, tóxica para los protagonistas. De alguna manera insinuando alternativas a las visiones normativas del parentesco, cada una de estas narrativas resalta la posibilidad de una ética eco-céntrica del cuidado, entendida como lo que Johns-Putra (2016) llama "un sentimiento, transformado en un ethos" de preocupación por las "necesidades de los demás, ya sean humanos o no humanos" (p. 129). De esta manera, modelos normativos (y antropocéntricos) de cuidado quedan relegados a los márgenes del foco de atención, apareciendo, en cambio, una ética de cuidado dentro de un marco múltiple-especies.

Ni Rossi ni Schweblin ofrecen un final esperanzador, recuperador o (tecno-) optimista para su lector. De hecho, sugiero que ambas narrativas parecen dar la bienvenida al fracaso reproductivo y el fin de la humanidad, o al menos, el fin de cierta versión de la humanidad. Al comprometerse con la idea de "fines" y al registrar las ansiedades ambientales contemporáneas, al mismo tiempo evitan reproducir finales "ecófobos" (Estok, 2009) o "necrofuturistas" (Canavan, 2014). En cambio, establecen el tono afectivo para aprender a vivir con lo que Nicole Merola (2018) llama "ansiedad antropocénica", una mezcla inquietante de melancolía, ira y resignación que equivale a una "admisión de lo eco-desagradable" (p. 32). Abrazando las implicaciones negativas del pensamiento antropocénico en lugar de recurrir a una lógica esperanzadora, estos relatos exigen el destronamiento de Anthropos, haciéndose eco del eslogan de Donna Haraway: "generar parientes, no bebés" (2015, p.162).

La escritora costarricense Anacristina Rossi empuja la idea de la extinción humana al límite, situando su cuento "Abel" en el centro de Centroamérica después del fin del mundo. ${ }^{7}$ Una de las escritoras más importantes de Costa Rica, Rossi es mejor conocida por su novela de "testimonio ecofeminista" La Loca de Gandoca (1992), que "contrarresta la lógica de la dominación patriarcal con una ética étnica y ambiental que considera nuevas formas de relación entre sujetos humanos y no humanos" (Kearns, 2016, p.98). En marcado contraste con la rica biodiversidad representada en La Loca de Gandoca, la premisa del cuento "Abel" lleva la crisis climática contemporánea a su conclusión lógica, dejando a la humanidad al límite

\footnotetext{
7. "Abel" es el primero de una serie de tres cuentos sobre una joven protagonista llamada Lalia. Esta historia fue publicada en una antología de ciencia ficción costarricense de 2013 llamada Lunas en vez de sombras y otros relatos de ciencia ficción. No he podido obtener una copia de este libro, pero la autora tuvo la amabilidad de enviarme un pdf del cuento, así como sus otros dos cuentos, de los cuales solo el último, "La Esperada”, tiene páginas numeradas.
} 
de la extinción. Oscilando entre la narración en primera y tercera persona, la historia relata las experiencias de una joven que parece ser la única superviviente de la especie humana. A través de una reconstrucción narrativa de la memoria de Lalia, se desarrolla la historia de un apocalipsis catastrófico, aunque lento: es una historia inquietantemente familiar para lectores contemporáneos, sobre poderes imperiales cambiantes, una serie de catástrofes climáticas, extinciones de especies, adaptaciones humanas y una larga lista de soluciones tecnocientíficas fallidas, culminando con el fin del oxígeno y, por lo tanto, el fin de la vida biológica del planeta. Lalia y su familia habían estado viviendo en una estación de investigación cerca del Canal de Panamá, pero a diferencia de sus padres científicos, su hermana y aparentemente de todos los demás humanos en la tierra, ella es la única que inexplicablemente ha sido capaz de adaptarse biológicamente a las condiciones cambiantes: absorbe agua a través de su piel, cada vez más porosa y parecida a la de un anfibio, y puede sobrevivir comiendo los capullos de un solo tipo de flor que también se ha adaptado para prosperar sin oxígeno.

Lalia es testigo de cómo mueren todos y todo lo que la rodea, incluidas las lombrices de tierra asfixiadas que desentierra mientras entierra a su familia. Después de esperar en la cima de un volcán para permitir que el olor de la materia orgánica en putrefacción se disipe, Lalia decide dirigirse a lo que alguna vez fue la ciudad capital, para ver si puede encontrar algún otro "ser" (Rossi, 2013). Curiosamente, Lalia no dice ser humano. Al inspeccionar la ciudad media sumergida y en ruinas, se sorprende al encontrarse con otro superviviente humano: su propio hermano. Abel ha regresado al hemisferio sur a través del estrecho de Bering, después de estudiar el permafrost ártico. ${ }^{8}$ Lejos de ser una feliz reunión familiar, hay un trasfondo oscuro en este reencuentro y Lalia relata en primera persona su sensación inmediata de pavor. Cuando su hermano mayor se maravilla de cómo se ha convertido en una joven atractiva, Lalia siente náuseas. Por primera vez, recurre a tomar una de las pastillas antidepresivas distribuidas entre la población para evitar el pánico masivo en el fin del mundo. Ansiosa por alejarse de su hermano, Lalia se atrinchera en el dormitorio de un hotel abandonado donde se refugian para pasar la noche. En la oscuridad, escucha que alguien intenta entrar en su habitación: "Entonces el terror que le había entrado al encontrarse con Abel se convirtió en una certeza. Ese era su futuro, lo que le tocaba...Porque esto iba más allá del cambio climático. Su hermano la iba a obligar a reproducirse con él" (Rossi, 2013). Antes del amanecer, Lalia toma un cuchillo de la cocina del hotel y degüella a su hermano mientras duerme, como si fuera, como ella dice, un "animal". A pesar de que este acto fratricida le provoca intensos sentimientos de repugnancia (le hace "vomitar y vomitar"), Lalia sigue insistiendo en que nunca se reproduciría con su hermano, "Ni siquiera si ése era el único modo de que continuara la humanidad" (ibid). La historia termina, algo abruptamente, con Lalia eligiendo deliberadamente la extinción al matar a su única posible pareja

\footnotetext{
8. Es significativo que Rossi sitúa su cuento en las Américas ecuatoriales: entrando en diálogo con la noción de que las poblaciones humanas de las Américas vinieron del norte, y a través del Estrecho de Bering, los sobrevivientes humanos de Rossi habitan el sur, invitando a una recuperación de las epistemológicas de los pueblos indígenas. que han sido sumergidos, dominados, borrados y/o sobrescritos.
} 
reproductora.

La decisión de Lalia de cometer fratricidio también se puede interpretar como un suicidio de especie, ya que, como señala Haraway (2007): "la supuesta responsabilidad autodefinida de la mujer hacia 'la especie', como hembra singular y tipológica, se reduce a su función reproductora" (p.18). A pesar de que ella es el único miembro restante de lo que se ha convertido en una especie en extinción, Lalia se niega a ceder a las "normas occidentales del imperativo reproductivo de las mujeres" desafiando la presunción de que "todos los organismos pueden y deben ejercer sus capacidades reproductivas para resistir la extinción" (Mitchell, 2015, $\mathrm{np}$ ). Dando un giro femenino al hermano del bíblico Abel, Caín, en lugar de instigar un nuevo linaje de engendramiento post-apocalíptico para repoblar la tierra, Lalia se niega a participar en la reproducción de los modelos patriarcales de la sociedad humana, ya que, hasta donde ella sabe, el linaje humano terminará con su propia extinción. La máxima "aguafiestas feminista" (para tomar prestado el concepto de feminist killjoy de Sara Ahmed, 2017), Lalia se niega radicalmente a participar en el futuro humano si eso significa la réplica de relaciones de género y parentesco del estatus quo.

Sin embargo, la historia de Lalia no termina ahí: dos cuentos más, llamados "La Incompleta" (2015) y "La Esperada" (2019), profundizan y complican la preocupación de Rossi por la extinción, la reproducción y la agencia femenina, y lo que esto significa para la protagonista, así como para el futuro de la humanidad. "La Incompleta" comienza donde termina "Abel": Lalia acaba de terminar con su mejor esperanza de continuidad familiar (y de especie) mientras los niveles del mar y las temperaturas globales continúan aumentando. Sintiendo una sensación de "soledad" pero "no arrepentimiento", Lalia decide seguir viajando hacia el sur, esta vez hacia terrenos más altos en Colombia para continuar su búsqueda de otros seres vivos. Aquí encuentra a otros dos supervivientes, Tami y Argos, y los tres eventualmente forman una especie de unidad triangular de parentesco. Lalia está desconcertada por la intensa atracción sexual que comienza a sentir hacia Argos, algo que describe como un deseo completamente físico de "dormir juntos. Tener hijos con él" (Rossi, 2015, np). Sin embargo, Argos no muestra ningún interés en sus avances sexuales y le dice que "no somos viables" en un sentido reproductivo.

Lalia descubre que Tami y Argos de hecho son "mutantes" partogénicos, supervivientes masculinos que se han adaptado biológicamente para reproducirse asexualmente. Curiosamente, todavía se consideran hombres, pero sus penes son "un colgajo inútil, una reminiscencia" (Rossi, 2015, np). Le explican que están en medio de un proceso acelerado de evolución del homo sapiens sapiens (una especie que ha demostrado ser cruel, egoísta y, en última instancia, suicida) a "algo menos egoísta y más compasivo e inteligente" (ibid). Lalia llama a esta nueva especie homo sapiens discriminans. Sin embargo, sus episodios reproductivos asexuales aún no han resultado en descendientes viables, y Tami describe sus experiencias de reproducción fallida en términos monstruosos, refiriéndose a sus "productos" en lugar de bebés o descendientes. Lalia se apresura a señalarles que los sentimientos que describen (náuseas, dolor físico, ambivalencia emocional) simplemente hacen eco de la experiencia de parto que las mujeres han sufrido durante milenios. Afirmando que preferiría morir antes que volver a sentir ese tipo de dolor, Tami 
ingiere hormonas masculinas artificiales para evitar los episodios reproductivos y, en última instancia, intenta suicidarse para escapar de la terrible experiencia. Por otro lado, a pesar de los avances sexuales de Lalia hacia él, Argos decide aventurarse por su cuenta, diciéndole a Lalia: "Tienes deseo pero no sé si estás equipada para la reproducción sexual," y, "si veo a alguien como tú, te avisaré" (Rossi, 2015, np), lo que sugiere que es incapaz de concebir el deseo físico o la reproducción más allá de un modelo de replicación a través de la díada de la diferencia sexual.

Como señala Joel Postema (2008) en su lectura de La Loca de Gandoca, en muchas de las historias de Rossi, "los personajes masculinos a menudo se adhieren a las estructuras de poder político que mantienen su autoridad" (p.122). El rechazo de Tami y Argos a la posibilidad de modos alternativos de reproducción de especies demuestra que, aunque estos hombres afirman haber "evolucionado", todavía son incapaces de imaginar o aceptar un cambio radical en las relaciones sexuales. Tami no está dispuesto a asumir el dolor de la reproducción, mientras que Argos no puede disfrutar de una relación íntima con Lalia sin que sea para fines reproductivos. Lalia simpatiza con Tami, reconociendo un paralelo entre su rechazo a reproducirse contra su voluntad y el propio asesinato de su hermano, pero al mismo tiempo, Lalia demuestra tener una confianza en la sabiduría de la naturaleza que Tami no comparte: contra la afirmación de Tami de que "la naturaleza esta experimentanto conmigo y no tiene derecho" Lalia piensa que la naturaleza "sabe" lo que esta haciendo forzando a un post-humano benevolente (es decir, un post-homo sapiens sapiens) a reproducirse. Ella le dice a Tami que se preocupará por él y sus "productos" como si fueran su propia familia, pero él no está dispuesto a participar en este escenario alternativo de parentesco. Tras el fallido intento de suicidio de Tami y su subsiguiente súplica de un asesinato por piedad, Lalia huye de su forma mutilada pero aún con vida: a pesar de que no se arrepiente de haber matado a su propio hermano, Lalia demuestra un total rechazo a matar a esta forma de vida potencialmente post-humana.

En la historia final titulada "La Esperada", Lalia conoce y se enamora de un científico indígena llamado Andrés, quien exhibe adaptaciones físicas similares al ambiente postapocalíptico que ha desarrollado Lalia. Él ha estado esperando su llegada, le dice, e inmediatamente se involucran en una relación intensamente física. A pesar de que Lalia hasta ahora estaba convencida de que no tiene futuro en el sentido reproductivo, Andrés insiste en su futuro como díada reproductora submarina: "tú y yo. Y el mar", le dice (Rossi, 2019, p. 110). En una especie de inversión de la narrativa evolutiva darwiniana, en esta historia el futuro de la humanidad implica un regreso a la "afinidad inmensa" (p.118) del océano. Sin embargo, a pesar de su vínculo con cosmovisiones indígenas, rápidamente se hace evidente que Andrés también es una figura que permanece alineada con las estructuras de poder que mantiene la autoridad masculina. Durante su transformación acelerada en seres acuáticos, Andrés comienza a atar a Lalia con una cuerda para que no salte al agua prematuramente y se ahogue. Cuando finalmente la deja de atar por las noches, Lalia nota con ironía que eso sucede porque él ha perdido la fuerza para atar a los nudos, y no porque ella se lo haya pedido (p. 121). Su reproducción de un acto violento contra una mujer por "su propio bien" (y quizás lo más importante, por el bien del futuro de la especie) 
aplasta efectivamente la libido de Lalia: "Que me amarrara en las noches fue demasiada violencia. Ya no pude volver a hacerle el amor", dice ella (p.120). Antes de que se completen sus transformaciones físicas y se conviertan en criaturas acuáticas, la luna de miel entre Andrés y Lalia llega a su fin. Cuando los cálculos científicos de Andrés fallan y se asfixia antes de que pueda hacer la transición al medio acuático, Lalia expresa indiferencia: "lo dejaría solo y esta especie que éramos, como se llamara, no se podría reproducir" (p. 120). No siente "tristeza por Andrés," pero en cambio se pregunta: “¿En qué me estaba transformando? (p.122). Cuando descubre que Andrés está inconsciente pero aún con vida, simplemente se pregunta si, después de su transformación en "bichos irreconocibles" del mar, seguirán siendo "apareables, pareja” o si ella “¿Iba a volver al principio de la evolución? ¿Iba a terminar siendo bacteria o arquea? (pp. 122-123).

Desde su acto fratricida como negación a reproducir el estatus quo de relaciones patriarcales, a su negativa a matar a Tami para poder dar la bienvenida a la posibilidad de formas de vida post-humanas, a su indiferencia hacia la posibilidad del futuro reproductivo con Andrés, las acciones de Lalia resuenan consistentemente con la idea de Colebrook (2012) de la "indiferencia sexual", es decir, "el pensamiento de producción y 'vida' que no toma la forma del organismo acotado que se reproduce a sí mismo en relación con su otro complementario" (p. 167). La adopción de Lalia de un futuro reproductivo sexualmente indiferente también resuena con el llamado de Elizabeth Grosz (2008) a la reapropiación feminista de Darwin con el fin de desarrollar una "comprensión feminista más politizada, radical y de mayor alcance de la materia, la naturaleza, la biología, el tiempo y el devenir" (p. 46). Colebrook sugiere que el modelo de vida darwiniano es "inmediatamente radical", ya que excluye el "determinismo biológico" y confronta "el pensamiento con el desafío de aceptar lo potencial de la novedad" (2008, p. 74). Sin duda, el mismo concepto de "especie" hace que "parezca que la reproducción sexual" es el mejor "medio para mantener la existencia de una forma de vida", cuando en realidad, "las formas de vida terrenales se involucran en una miríada de formas de reproducción" y, "en términos darwinianos, todas las especies que logran sobrevivir son igualmente exitosas" (Hird en Mitchell, 2015, np). Al desplazar la primacía de la reproducción sexual, se puede crear un espacio para visiones del futuro que van más allá de "nuestra cultura de pronatalismo desenfrenado" y hacia "nuevas posibilidades que no son esperanzadoras ni nihilistas, pero que tienen en cuenta un sentido de continuidad a través de un queering de las estructuras familiares y de la polipaternidad" (Colebrook \& Caroline 2016, np). Este es precisamente el tipo de relaciones de parentesco alternativo que la propia Lalia intenta imaginar con Tami y sus "productos" reproductivos.

Los últimos pensamientos conscientes de Lalia, finalmente sumergida bajo el agua en el último párrafo del cuento, consisten en preguntarse si la sensación de "unidad" con el océano que siente es resultado de sus adaptaciones físicas, o si "estaba muriendo...y estas sensaciones eran la última reacción química de mi cerebro" que la engaña para que sienta un "amor infinito" freudiano en los momentos finales antes de la muerte (Rossi, 2019, p. 123). Las últimas dos líneas del cuento dicen: "Dejamos de pensar. 0 dejamos de existir" (ibid). Es decir, o Lalia y Andrés han dejado de pensar ( $\mathrm{y}$, al menos en una vena cartesiana, por lo tanto, 
han dejado de ser humanos, habiendo mutado en algo que ya no es completamente humano), o han muerto y dejado de existir por completo, lo que también excluiría su futuro reproductivo como especie. Dadas las ansiedades antropocéntricas en torno a la reproducción y la (in)diferencia sexual, y dados "los señuelos y la pereza que la díada sexual como figura ha ofrecido para el pensamiento" (Colebrook, 2012, p.167), al final, hay poca diferencia. Ya sea que uno deje de existir o simplemente deje de existir como humano, el resultado final sigue siendo una especie de extinción humana.

El compromiso narrativo de Rossi con el fin de lo humano puede entenderse en términos de lo que Colebrook llama el "experimento mental de la extinción" (2014, p. 27) como una forma de desafiar las concepciones dominantes de la "humanidad" y "transformar las normas sociales y estructuras de poder que refuerzan desigualdades de género, sexualidad, raza y especie" (Mitchell, 2015, n.p). Los relatos de ciencia ficción feministas de Rossi se involucran con la extinción para realizar una crítica radical de la reproducción, mientras que al mismo tiempo se abren para abarcar posibilidades de vida no binarias. En conjunto, el arco narrativo de los tres cuentos muestra el cuerpo de Lalia cada vez más "marcado con vestigios corporales de los orígenes no humanos de la humanidad", conjurando una subversión que mira simultánea hacia adelante y hacia atrás de los "discursos humanistas teleológicos" y así evocando un "nuevo concepto de la humanidad en constante proceso de reconfiguración" (Coleman, 2016, p. 696). Como dice Jane Bennett (2010, p. 121):

Uno puede invocar colonias de bacterias en los codos humanos para mostrar cómo los sujetos humanos mismos son no-humanos, alienígenas, ajenos a la materialidad vital. Se puede notar que el sistema inmunológico humano depende de los gusanos helmintos parásitos para su correcto funcionamiento o citar otros casos de nuestra cyborgización para mostrar cómo la acción humana es siempre un conjunto de microbios, animales, plantas, metales, químicos, sonidos, etc. ${ }^{9}$

Como sugiere Rosi Braidotti, "lejos de marcar el rechazo, la extinción o el empobrecimiento de lo humano", sentarse con una visión incómoda de la extinción humana como un experimento mental podría ser una "forma de reconstituir lo humano", con el fin de volver a "negociar quiénes somos 'nosotros'" (2019, p. 39). Es decir, en lugar de interpretar el compromiso especulativo de Rossi con la extinción humana como un deseo misantrópico de muerte para la humanidad, tal vez podríamos verlo como un intento "disantropocéntrico" (Cohen 2015, p. 9) para dar paso a visiones de otro tipo.

Como sugiere Jeffrey Cohen (2015), un destronamiento "no indiferente, no misantrópico, sino desantropocéntrico" del ser humano tiene el potencial de hacer "bambolear historias centradas en el humano, [hacer que] sus trayectorias se

\footnotetext{
9 "One can invoke bacteria colonies in human elbows to show how human subjects are themselves nonhuman, alien, outside vital materiality. One can note that the human immune system depends on parasitic helminth worms for its proper functioning or cite other instances of our cyborgization to show how human agency is always an assemblage of microbes, animals, plants, metals, chemicals, word-sounds, and the like".
} 
desvíen" (p. 25). Este bamboleo o desvío se experimenta de una manera particularmente aguda e incómoda en la novela de eco-horror de Samantha Schweblin, Distancia de Rescate. ${ }^{10}$ La novela invita a múltiples lecturas: es a la vez un thriller psicológico sobre la estrecha y conflictiva relación entre madres y sus hijos pequeños; es una historia sobrenatural sobre la transmigración de las almas; y es un ejemplo gótico y anti-pastoral de lo que Gisela Heffes (2019) identifica como el "giro rural" hacia los espacios no urbanos en las novelas argentinas de la segunda década del siglo XXI. Se trata de una dinámica que invierte el mecanismo moderno según el cual "los espacios urbanos constituían el lugar clave para rechazar y limpiar la 'barbarie' profundamente arraigada en los territorios rurales", al llamar la atención sobre el hecho de que "el paisaje rural ya no es indómito; más bien, se ha convertido [en un lugar] antropogénicamente intervenido, recortado, explotado y domesticado" (pp. 55-56). En otras palabras, esta novela desconcierta las expectativas del lector al transformar el verde e idílico espacio del campo argentino en una pesadilla agrotóxica del siglo XXI. ${ }^{11}$

La narrativa de Distancia de Rescate se estructura como un diálogo ininterrumpido entre dos voces, la primera de una mujer (Amanda) inmóvil y confinada en una cama de hospital, y la segunda voz de un joven (David), que se arrodilla a su lado y la obliga a contar una serie de hechos recientes. Amanda no parece entender por qué no puede moverse, y David le explica que: "Por los gusanos. Hay que ser paciente y esperar. Y mientras se espera, hay que encontrar el punto exacto en que nacen los gusanos" (Schweblin, 2015). La voz de David es insistente, afirmando que "es importante, es muy importante para todos" (ibid) mientras persuade a Amanda a reconstruir sus recuerdos con mucho cuidado, dado que: "El punto exacto está en un detalle, hay que ser observador". En esta historia, lejos de ser un indicador de suelo sano, oxigenado y reproductivo, los "gusanos" a los que se refiere David son de otro tipo.

La metáfora central para el cuidado en este texto se puede encontrar en la preocupación de Amanda por lo que ella llama la "distancia de rescate", un cálculo en constante flujo sobre cuánto tiempo le tomaría llegar a su hija, Nina, en caso de una emergencia. Amanda se imagina unida a Nina por una cuerda o hilo invisible, que se acorta o alarga según la inmediatez percibida del peligro. Cuando Amanda reflexiona, "Necesito ir por delante de cualquier cosa que pudiera ocurrir," David le pregunta: "¿Por qué las madres hacen esto?" (Schweblin, 2015). Como señala Ana María Mutis (2020) en su lectura del texto, "hilos que se tensan, se rompen, acortan o desaparecen acechan en la historia como símbolos ominosos del frágil vínculo

10. Publicada en 2014, esta novela se tradujo al inglés como Fever Dream y fue nominada al Premio Internacional Man Booker 2017. Samantha Schweblin fue elegida por la revista Granta como una de las mejores escritoras de habla hispana menores de treinta y cinco años.

11. No uso la palabra "pesadilla" a la ligera aquí. La crítica de The New Yorker, Lia Tolentino, describió a la novela como una "emoción enfermiza", que está "brillantemente estructurada y aterradora" y que "pertenece a la categoría de novelas impresionistas breves que se consumen mejor de una sola vez" (yo desafiaría a cualquiera intentar no leer esta novela de una sola vez). Dada la proliferación de narrativas de terror ecológico que han provocado "reacciones viscerales" similares en los últimos años, podríamos empezar a preguntarnos: ¿será que el horror está emergiendo como el modo del Antropoceno? 
que une a una madre con su hijo" (p. 44). Sin embargo, el instinto de una madre de proteger a su hijo a toda costa claramente ya no es suficiente: a medida que se desarrolla la narrativa, descubrimos que la madre de David, Carla, tampoco ha logrado proteger a su hijo. Seis años antes, después de que el semental de su esposo muere al beber agua tóxica de un arroyo, Carla se horroriza al darse cuenta de que su pequeño David de alguna manera ha sido envenenado por la misma agua. Desesperada por encontrar una solución en ausencia de un sistema de salud pública adecuado, Carla lleva a David a una curandera de la comunidad, quien divide su espíritu y migra parte de él a un cuerpo sano, permitiendo a su vez que una parte de un espíritu desconocido entre en el cuerpo de David. Sobrevive, pero después del procedimiento David es diferente: es más frío y de alguna manera vacío, y exhibe comportamientos extraños y repetitivos. Su piel está cubierta de imperfecciones que son casi imperceptibles, pero según Carla, ya no es su hijo, sino que se ha convertido en un "monstruo" (Schweblin, 2015).

Mutis lee Distancia de Rescate a través de su adhesión a las convenciones de la ficción gótica para dilucidar la capacidad de la novela de "dar visibilidad a amenazas invisibles" (2020, p. 41). Esto ocurre principalmente a través de la figuración del "niño monstruo que, a través de su conexión con el eco-zombi, materializa la alienación que resulta de la manipulación del medio ambiente" (p.55). Los "dobles" monstruosos que resultan de las almas transmigradas de los niños (intercambiables) no solo transforman lo "familiar en misterioso hasta un extremo íntimo", sino que también funciona como una "metáfora de la contaminación", ya que la "propagación incontrolada de venenos agroquímicos" es comparada con "la dispersión de almas que invaden cuerpos extraños" (p. 42). La figura del niño ofrece una "escala humana para demostrar la escala temporal de la violencia lenta" y de esta manera, la novela es capaz de evocar la "violencia lenta" de Rob Nixon (Cecire en Mutis, 2020, p. 50), ya que los efectos de la contaminación ambiental se dispersan durante largos períodos de tiempo, no son visibles ni de interés sensacionalista y, por lo tanto, no se entienden como violencia per se.

Schweblin imagina un fracaso total en cuanto al cuidado materno y el cuidado social: como sugiere el crítico Manuel Allasino (2018), la novela "sigue una vertiginosa fatalidad haciéndose siempre la misma pregunta: ¿Hay acaso algún apocalipsis que no sea el personal?" (np). Al final de la historia, Amanda presumiblemente está muerta, Carla ha desaparecido inexplicablemente, y sus hijos (o lo que queda de ellos) están en las manos ineficaces de sus inconscientes-y, al menos hasta los últimos párrafos en gran parte ausentes-padres. El trágico fracaso de Amanda y Carla para proteger a sus propios hijos dice algo crucial sobre el vínculo entre las prácticas de maternidad y las prácticas de cuidado ecológico. Mutis, 2020 sugiere que emplear la "figura del niño desaparecido" no es solo una forma de "hacer visible y urgente la lenta violencia de la contaminación por agroquímicos", sino que también es una forma de "politizar la maternidad para hacer avanzar un mensaje ecológico" (p. 43). ${ }^{12}$ Sin

\footnotetext{
12. La politización de la pérdida maternal es algo familiar en el contexto argentino: el surgimiento de las Madres de la Plaza de Mayo, como respuesta a la ruptura de los lazos maternos y de parentesco que se produjo durante la dictadura militar de 1976 a 1983, "insertó la figura de la madre en la esfera política argentina modificando el lugar de enunciación del discurso materno"
} 
embargo, como advierte Cate Sandilands (en Mitchell, 2015, np), las nociones esencializadoras de maternidad y cuidado como un medio para proteger a las generaciones futuras "restringen la acción política de las mujeres a la esfera privada de la familia y las interacciones interhumanas", lo que a su vez restringe "el sentido ético-político de la agencia de las mujeres frente al fenómeno multi-especies...que es la extinción". De hecho, paralizada dentro de su espacio individual de pánico y preocupación materna, Amanda pierde toda capacidad de acción significativa. La representación en el texto de los esfuerzos desesperados (pero en última instancia inútiles) de estas madres para proteger a sus propios hijos del peligro revela lo equivocado que es culpar las fallas de cuidado al ámbito privado de la familia, en lugar de identificar explícitamente las responsabilidades públicas para el bienestar de los niños. En el caso de esta novela, se trata de una combinación catastrófica de regímenes agro-farmacológicos, modos de producción capitalistas y una peligrosa falta de protecciones sanitarias públicas. Al enfatizar repetidamente que lo que está en juego es "importante para todos", David le dice a Amanda que nada de lo que le ha sucedido es culpa de su madre: "se trata de algo mucho peor", dice. Pero la novela nunca revela explícitamente qué es ese "algo peor". Toda la narrativa gira en torno a la imposibilidad de representación, de la "dificultad de decir lo indecible," y así como Amanda está figurativamente "atada a una narrativa que no llega a ninguna conclusión" (Mutis, 2020, p 41), también está literalmente atrapada en su cama de hospital-y dentro de su propio cuerpo envenenado-e incapaz de avanzar. Resonando con lo que Lawrence Buell llama "discurso tóxico", la novela de Schweblin subraya la idea de que "los cuerpos devastados por enfermedades (...) también son incapaces de reproducirse, abortando así la idea de un futuro" (Heffes, 2019, p. 70).

La tendencia crítica de interpretar este texto principalmente a través de un lente centrado en las tensas relaciones madre-hijo en la novela, corre el riesgo de hacernos como lectores, culpables de la repetida acusación de David a Amanda: de que nos estamos perdiendo lo que es realmente "importante para todos". Así es como la novela arrastra nuestra visión de túnel antropocéntrica a la luz del día, al resaltar el problema que solamente somos capaces de preocuparnos por cuidar lo que es "como" nosotros. Por eso creo que es importante contrastar los modelos procreacionales de cuidado materno en la novela con el modelo de cuidado trans- 0 inter-especies que es modelado por David (y en menor medida, por Nina/David al final). En la transmigración de sus almas, ambos niños ya no son la descendencia individual de Amanda y Carla, sino que se han transformado en algo más, algo plural, híbrido, algo más que humano. Después de la transmigración, David comienza a matar, llorar y enterrar a los animales envenenados y moribundos que lo buscan. El modelo de cuidado que encarna es simplemente ininteligible para su madre, que se horroriza completamente cuando comienza a ayudar a "empujar" a estas criaturas moribundas por el umbral hacia la muerte, comenzando con patos, pasando a perros, caballos y, finalmente, a Amanda misma. En su íntimo parentesco con estas almas sufridas que están atrapadas — como él mismo- entre los vivos y

(Domnigues en Mutis 2020, p. 44). Sin duda, en esta novela, la noción de que el alma del niño está de alguna manera "en otra parte" pero "se niega a desaparecer por completo comparte con los desaparecidos su ausencia presente y la incertidumbre de su destino" (p.45). 
los muertos, David se convierte en un monstruo para su madre. Pero, aun así, este acto cuidadoso de "empujarlos" demuestra el nivel de compasión más-que-humano de David.

Yuxtapuestos a las "cuerdas" imaginarias de la distancia de rescate de Amanda, en una de las escenas finales y más desgarradoras de la novela nos damos cuenta de los intentos desesperados de Nina / David para literalmente mantener sus redes de parentesco (imaginadas a través del tropo de fotografías familiares) con hilo sisal. En su trabajo sobre "la ética especulativa en mundos de vida más-que-humanos", María Puig de la Bellacasa (2017) sugiere que "nada se mantiene unido sin relaciones de cuidado" (p. 67). La solidaridad de David con los animales, humanos y no humanos, ilustra una preocupación por la tierra y todas las formas de vida que la habitan. Para Colebrook (2009) "solo pensando en intensidades más allá de lo humano podemos empezar a vivir éticamente" (p. 250), mientras que Haraway (2003) nos recuerda que los "actores, así como los actantes, vienen en muchas y maravillosas formas", y que la "'reproducción'-o menos inexactamente, la generación de formas novedosas-no necesitan ser imaginadas en los aburridos términos bipolares de los homínidos" (p. 299). Siguiendo el ejemplo de la perspectiva más-que-humana de David, podría ser posible, quizás, pensar en "generar parentesco" con los monstruos.

En su reseña de la novela, Carlos Pardo (2015) sugiere que Distancia de Rescate nos invita a repensar nuestro "imaginario del peligro" porque, al crear un paralelo sutil entre la siembra de cultivos de soja transgénica y los temores de los padres a la deformación física y mental de sus hijos, "la 'distancia de rescate' se transforma en el vulnerable espacio del cuidado del humanismo burgués, una familiaridad con el mundo ya perdida" (np). A esto añadiría: aunque todavía no nos damos cuenta de lo que ya se ha-o está en proceso de ser-perdido. Colebrook (2014) sugiere que "la postulación de la era del Antropoceno se basa en mirar nuestro propio mundo e imaginar como será cuando se haya convertido en pasado" (p. 26). Tom Cohen (2016) señala que el mismo término "Antropoceno" ya implica una especie de "tardanza" [too-lateness], ya que "sólo puede anticiparse o legitimarse a partir de un reconocimiento futuro del mismo, después de que se consuma la desaparición que implica" (p. 23). Tales ansiedades temporales impregnan Distancia de Rescate, así como los cuentos de Rossi: Lalia se lamenta “ $\mathrm{El}$ tema de siempre, demasiado tarde!” (Rossi, 2019, p. 121), mientras que Amanda ya está dada por muerta cuando David la insta a atar los hilos sueltos de su historia. Amanda permanece suspendida en su narración, incapaz de avanzar o retroceder, y David le dice "Lo importante ya pasó. Lo que sigue son solo consecuencias. ¿Por qué sigue entonces el relato? [le pregunta Amanda] Porque todavía no estás dándote cuenta. Todavía tenés que entender" (Schweblin 2015). Al igual que a Lalia, a Amanda se le da una pastilla y se le dice que duerma una siesta. El arco narrativo termina sin que ella pueda establecer la conexión entre su muerte y el "punto exacto" en el que emergen los gusanos, así como nunca menciona directamente los horrores reales que sustentan la novela, es decir, el uso indiscriminado de agroquímicos en los cultivos de soja transgénica que está envenenando a los niños de las zonas rurales de Argentina. ${ }^{13} \mathrm{Al}$ igual que los niños zombis con deformidades

\footnotetext{
13. Como señala Mutis (2020): "la pesadilla del ecocídio que describe la novela se remonta a 1996, el
} 
inexplicables que pueblan la novela, los horrores ecológicos solo pueden acechar los márgenes de la narrativa, nunca nombrados explícitamente. De esta manera, Schweblin levanta un espejo para que sus lectores puedan captar un atisbo aterrador (aunque fugaz y distorsionado) de nuestra condición contemporánea, colocándonos como lectores en la posición desconcertada y desesperada de la protagonista. Al igual que Amanda, nunca podemos volver a unir por completo los fragmentos de la historia. En un momento, una de las madres reflexiona: "Los miedos que nos conmueven no son los que realmente deberíamos tener". También como Amanda, nosotros, como lectores, seguimos siendo en gran parte incapaces de comprender el alcance total de la pérdida de especies y la destrucción ambiental que nos hemos provocado, y por lo tanto somos fácilmente manipulados para preocuparnos profundamente por asuntos que parecen importantes, pero que de hecho simplemente nos distraen de preocuparnos por, o cuidar, las cosas que son realmente "importantes para todos", como señala la ética más-que-humana de David.

En última instancia, ni Distancia de Rescate ni "Abel" proporcionan finales felices para sus protagonistas en aras del cierre narrativo: por el contrario, ambiguos y potencialmente incómodos, ambos finales abiertos invitan a los lectores a repensar cuestiones de responsabilidad ética, específicamente adoptando el potencial negativo de las ficciones antropocénicas. Los niños monstruosamente dobles y no individualizados de Schweblin, y la narradora anfibia y ya no completamente humana de Rossi, resuenan con la teoría de Stacy Alaimo (2018) de la "trans-corporeidad," que es la idea que "todas las criaturas, como seres encarnados, están entrelazados con el dinámico mundo material, que los atraviesa, los transforma y es transformado por ellos"; de esta manera, desafían "el sujeto soberano del individualismo humanista occidental, que se imagina a sí mismo como trascendente, desencarnado y alejado del mundo que contempla" (pp. 435-436). En el caso de los protagonistas de Schweblin y (quizás) Rossi, estos procesos transcorpóreos son literalmente fatales: pero cada relato apunta a la posibilidad de otro tipo de relación entre los humanos y su mundo. Esta relación podría entenderse a través del sentido de "intra-acción" de Karen Barad (2003), donde las cosas no están ordenadas en una relación sujeto-objeto (donde una subsume a la otra) sino que, en cambio, están abiertas a la acción entre las cosas a través de la relacionalidad y la igualdad ontológica. Como sugiere Haraway (2003), "la naturaleza está hecha, pero no completamente por humanos; es una co-construcción entre humanos y no humanos” (p. 298).

Haraway también nos recuerda que "no es un final feliz lo que necesitamos, sino un final sin fin. Es por eso que ninguna de las narrativas de apocalipsis patriarcales masculinistas servirá" (2003, p. 327). He sugerido que las visiones especulativas y abiertas de Rossi y Schweblin sobre el "fin" de los humanos pueden ayudarnos a mantener la pregunta de Braidotti-"¿quién es este 'nosotros' cuya humanidad está en juego?" (2019, p. 86) -a la vanguardia de nuestras mentes. Como sugiere Serenella Iovino (2018), en "nuestra época 'postgeológica', llámela

año en que la soja genéticamente modificada de Monsanto fue aprobada en Argentina como parte integral de un nuevo modelo de agricultura", lo que aumentó la "producción de soja transgénica y, en consecuencia, el uso de glifosato" (p.39). 
Antropoceno, Plantationoceno o Capitaloceno", la idea de descentrar Anthropos "significa literalmente desviar nuestras prioridades, liberando los cuerpos de la naturaleza mundial de los delirios discursivos y materiales en las narrativas centradas en el ser humano" (p. 115). La "marca del posthumanismo", sugiere Sheryl Vint (2007), reside en una "apertura al cambio y la novedad, en convertirse en otro y a renunciar a las viejas categorías cuando ya no sirven, en lugar de defenderlas contra el cambio inevitable" (p. 175). Contemplar la desaparición del homo sapiens como ejercicio de la imaginación obliga a uno a preguntarse, ¿qué otras formas de vida podrían evolucionar a partir, o en lugar, de la "humanidad" tal como la conocemos? Así, el énfasis de Rossi sobre la extinción figurativa, tal como el modelo de cuidado más-que-humano de Schweblin, pueden leerse como invitaciones a imaginar formas nuevas y "no explotadoras" de "unión" humana-no humana (Puig de la Bellacasa, 2017, p. 240), hacia lo que Braidotti llama una "perspectiva planetaria geocéntrica" (2019, p. 81). Al proporcionar un espacio imaginativo más allá de la lógica del excepcionalismo humano, estas dos eco-ficciones latinoamericanas invitan a sus lectores a comprender que en algún lugar entre lo "ya es tarde" de la culpabilidad antropogénica y el "no todavía" de los futuros posibles, aún pueden haber espacios para que emerjan narrativas alternativas sobre futuros potencialmente más cuidadosos.

\section{Referencias}

Ahmed, S. (2017). Living a Feminist Life. Durham and London, UK: Duke University Press.

Alaimo, S. (2018). Trans-Corporeality. En R. Braidotti y M. Hlavajova (Ed.), The Posthuman Glossary (pp. 435-438). London and New york: Bloomsbury.

Allasino, M. (2018) Distancia de rescate, el hilo vital que nos une a nuestros hijos. La Tinta. Recuperado de: https://latinta.com.ar/2018/03/distancia-rescate-hilo-vital-nos-une-hijos/

Barad, K. (2003) Posthumanist Performativity: Toward an Understanding of How Matter Comes to Matter. Signs: Journal of Women in Culture and Society, 28(3), pp. 802-831.

Bennett, J. (2010). Vibrant Matter: A Political Ecology of Things, Durham and London, UK: Duke University Press.

Braidotti, R. (2013). The Posthuman. Cambridge, UK: Polity Press.

Canavan, G. (2014). 'If the Engine Ever Stops, We'd All Die': Snowpiercer and Necrofuturism Paradoxa, (26).

Cohen, T. (2016). Trolling 'Anthropos' Or, Requiem for a Failed Prosopopeia. En Twilight of the Anthropocene Idols. (pp. 20-80). London, UK: Open 
Humanities Press.

Cohen, J. (2015). Stone: An Ecology of the Inhuman. Minneapolis, U.S.A.: University of Minnesota Press.

Colebrook, C. \& Caroline, J. (2016). Interview, The Brooklyn Rail. Recuperado de: https://brooklynrail.org/2016/09/art_books/claire-colebrook-with-jessica -caroline

Colebrook, C. (2014). Death of the Posthuman: Essays on Extinction Vol. 1. Open Humanities Press. Michigan, U.S.A.:University of Michigan Library.

Colebrook, C. (2012). Sexual Indifference. En T. Cohen (Ed.), Telemorphosis: Theory in the Era of Climate Change. Vol. 1 Open Humanities Press. Ann Arbor, Michigan, U.S.A.: University of Michigan Library

Colebrook, C. (2009). On the Very Possibility of Queer Theory En C.Nigianni y M. Storr (Eds.), Deleuze and Queer Theory (pp. 11-23). Edinburgh, Scotland: Edinburg University Press.

Colebrook, C. (2008) On Not Becoming Man: The Materialist Politics of Unactualized Potential En S. Alaimo y S. Heckman (Eds.) Material Feminisms (pp.52-84). Bloomington and Indianapolis: Indiana University Press.

Coleman, V. (2016) Becoming a Fish: Trans-Species Beings in Narrative Fiction of the Southern Cone. ISLE: Interdisciplinary Studies in Literature and Environment, 23(4), pp. 694-710.

Edelman, L. (2004). No Future: Queer Theory and the Death Drive. Durham, UK: Duke University Press.

Estok, S. (2009). Theorizing in a Space of Ambivalent Openness: Ecocriticism and Ecophobia. ISLE, 16 (2), pp. 1-23.

Grosz, E. (2008). Darwin and Feminism: Preliminary Investigations for a Possible Alliance En S. Alaimo y S. Heckman (Eds.),Material Feminisms(pp. 23-51). Bloomington and Indianapolis: Indiana University Press.

Haraway, D.. (2015). Anthropocene, Capitalocene, Plantationocene, Chthulucene: Making Kin Environmental Humanities, 6: pp.159-165.

Haraway, D. (2007).When Species Meet. Minneapolis, U.S.A.: University of Minnesota Press.

Haraway, D. (2003). The Promises of Monsters: A Regenerative Politics for Inappropriate/d Others.En J. A. Weinstock (Ed.), The Monster Theory Reader (pp. 459-521) Minneapolis; London, U.K.: University of Minnesota Press. 
Heffes, G. (2019). Toxic Nature in Contemporary Argentine Narratives: Contaminated Bodies and Ecomutations. En I. Kressner, A.M. Mutis y E.M. Pettinaroli (Eds.), Ecofictions, Ecorealities and Slow Violence in Latin America and the Latinx World. (pp.55-73). New York, U.S.A.: Routledge.

Hunt, E. (2019). BirthStrikers: meet the women who refuse to have children until climate change ends. The Guardian. March 12. Recuperado de: https://www.theguardian.com/lifeandstyle/2019/mar/12/birthstrikers-m eet-the-women-who-refuse-to-have-children-until-climate-change-ends

Iovino, S. (2018). (Material) Ecocriticism. En R.Braidotti y M. Hlavajova (Eds.), The Posthuman Glossary (pp.112-115). London and New York: Bloomsbury.

Iovino, S y Oppermann, S. (2012). Material Ecocriticism: Materiality, Agency, and Models of Narrativity. Ecozon@ European Journal of Literature Culture and Environment, 3 (1), pp. 75-91.

Johns-Putra, A. (2016). My Job Is to Take Care of You: Climate Change, Humanity, and Cormac McCarthy's The Road. MFS Modern Fiction Studies, 62(3), pp. 519-540.

Johns-Putra, A. (2014). Care, Gender and the Climate Changed Future: Maggie Gee's The Ice People. En G. Canavan y K. S. Robinson (Eds.), Green Planets: Ecology and Science Fiction (pp.127-142). Middleton, U.S.A: Wesleyan University Press.

Kearns, S. (2016). Widening the Spectrum of Desire and Nation: Anacristina Rossi's Fiction QED: A Journal in GLBTQ Worldmaking 3 (2), pp. 93-106.

Merola, N. M. (2018). Juliana Spahr and Anthropocene Anxiety. En K. Bladow y J. Ladino (Eds.).Affective Ecocriticism: Emotion, Embodiment, Environment (pp.25-64). Lincoln and London: University of Nebraska Press.

Mitchell, A. (2015). Gendering Extinction Worldly wordpress.com. Recuperado de: https://worldlyir.wordpress.com/tag/sixth-mass-extinction/

Mutis, A. M. (2020). Monsters and Agrotoxins: The Environmental Gothic in Samantha Schweblin's Distancia de Rescate En I. Kressner, A.M. Mutis y E. Petinaroli (Eds.) Ecofictions, Ecorealities and Slow Violence in Latin American and the Latinx World (pp. 39-54). New York and London: Routledge.

Pardo, C. (2015). Los hijos tóxicos: crítica de Distancia de Rescate. El Pais Cultura. 7 March. Recuperado de:

https://elpais.com/cultura/2015/03/05/babelia/1425551789 495804.ht $\underline{\mathrm{ml}}$

Postema, J. (2008). Ecology and Ethnicity in Anacristina Rossi's La loca de Gandoca. 
Cincinnati Romance Review, 27, pp. 113-24.

Puig de la Bellacasa, M. (2017). Matters of Care: Speculative Ethics in More than Human Worlds. Minneapolis, U.S.A.: University of Minnesota Press.

Rossi, A. (2013). "Abel" Lunas en vez de sombras y otros relatos de ciencia ficción. San José, Costa Rica: EUNED.

Rossi, A. (2015). La Incompleta Te voy a recordar, relatos de ciencia ficción. San José, Costa Rica: EUNED.

Rossi, A. (2019). La Esperada. Protocolo Roslin y otros relatos de ciencia ficción. San José, Costa Rica: Editorial Costa Rica.

Schweblin, S. (2015). Distancia de Rescate. Random House (Kindle Edition).

Tolentino, L. (2017). The Sick Thrill of Fever Dream, The New Yorker. Recuperado de:https://www.newyorker.com/books/page-turner/the-sick-thrill-of-fever -dream.

Trexler, A. (2015). Anthropocene Fictions: The Novel in a Time of Climate Change. Charlottesville and London: University of Virginia Press.

Vint, S. (2007). Bodies of Tomorrow: Technology, Subjectivity, Science Fiction. Toronto, Canadá: University of Toronto Press. 